\title{
Magnitude of burnout and its associated factors among nurses working in public hospitals of Amhara regional state, Ethiopia
}

\begin{abstract}
Background: Nurses are exposed to professional burnout due to their exposure to physical, mental, and emotional stressors, which can lead to numerous complications in their personal, social, and organizational life.

Objectives: To assess the magnitude of nurses' burnout and its associated factors in public hospitals of Amhara regional state, Ethiopia.

Methodology: Institutional based cross-sectional study design was conducted on 369 nurses selected by systematic sampling technique. A structured self-administered Amharic version questionnaire was used. Data was, coded and entered in Epi data version 3.7 and analysed by SPSS version 22 software. Descriptive statistics was used to describe the variables. Multivariate analysis, AOR, $95 \% \mathrm{CI}$ and $\mathrm{p}$-value $<0.05$ were used to identify variables which had significant association with dependant variable. Permission was obtained from Institution Review Board (IRB) of Addis Ababa University. Information obtained from participants was kept secured and confidential.
\end{abstract}

Result: A total of 369 participant nurses were included in this study, with response rate of $100 \%$, from these respondents 186 nurses (50.4\%) were suffered from professional burnout. There is significant association between burnout and educational status [AOR $=3.66 ; 95 \%$ CI: $(1.11,12.01)]$, service year [AOR $=1.94 ; 95 \%$ CI: $(1.11,3.38)]$, work load $[\mathrm{AOR}=0.43$; $95 \%$ CI: $(0.19,0.99)$, intention to leave their work [AOR $=0.41 ; 95 \% \mathrm{CI}:(0.25,0.67)$, health status [AOR $=2.27 ; 95 \% \mathrm{CI}:(1.18,4.37)]$ and health problems $[\mathrm{AOR}=2.32 ; 95 \% \mathrm{CI}:(1.14$, 4.73)] had association to nurses' professional burnout.

Conclusion: This study shows that high proportion of nurses were suffer from burnout due to their work. This study also showed that there is a significant association between factors such as educational status, service year, workload, intention to leave their work, current health status, and health problems and professional burnout.

Keywords: professional burnout, nursing, exhaustion, problems and professional, proportion of nurses
Volume 8 Issue 2 - 2019

\author{
Destaye Gashaw Adbaru,' Zuriyash Mengistu \\ Assen, ${ }^{2}$ Tefera Mulugeta Demelew, ${ }^{2}$ Girum \\ Sebsibie Teshome ${ }^{2}$ \\ 'College medicine of Health Sciences, Hawassa University, \\ Ethiopia \\ ${ }^{2}$ College of Health Sciences, Addis Ababa University, Ethiopia
}

Correspondence: Girum Sebsibie Teshome, College of Health Sciences, Addis Ababa University, Addis Ababa, Ethiopia, Email girumseb@gmail.com

Received: December 05, 2018| Published: March 26, 2019
Abreviations: DP, depersonalization; EE, emotional exhaustion; JDCS, job demand control support; MBI, maslash's burnout inventory; MBI-HSS, maslash's burnout inventory-human survey service; PA, personal accomplishment; PTSD, post-traumatic stress syndrome

\section{Introduction}

Burnout is a concept that can be defined differently by different individuals. Before it got standardized definition by Maslach, different people used the term to mean different things. According to Maslach (1982), burnout is a state of emotional exhaustion, depersonalization and reduced sense of personal accomplishment that occurs among individuals who work with people in some capacity as result of chronic exposure to stress resulting from human interaction. ${ }^{1}$ As a result; burnout has three dimensions. The first dimension of the burnout syndrome is "emotional exhaustion". When the emotional reserves are depleted, employees feel that they are no longer able to provide work of good quality. They have feelings of extreme energy loss and a sense of being completely drained out of emotional and physical strength. The second dimension "depersonalization" is defined as the development of negative attitudes, such as cynicism and negativism, both in thinking as well as in behaviour, in which co-workers and service recipients are approached with derogatory prejudices and treated accordingly. The third aspect is "lack of personal accomplishment". This is defined as lack of feelings regarding both job and personal competence and failure in achieving goals. ${ }^{1}$ there is a general consensus in the literature that emotional exhaustion is the central or core dimension of burnout. ${ }^{2}$

The issue of burnout among nurses is familiar. Nursing is inevitably a stressful profession. The prevalence of burnout in nursing is a real issue and a real threat to the health care system. Several studies around the world in different continents have been carried out showing the high rates of burnout among nurses, more especially staff nurses working in hospitals. ${ }^{3}$ Nurses have tremendous responsibilities and deal with enormous challenges. ${ }^{4}$ It is reported that nurses are more prone to developing stress than other health care professionals. Burnout is unfortunately one of the challenges that many nurses in different parts of the world are facing today. ${ }^{5}$

In 2010, a cross national investigation study was conducted across six countries: United States, Germany, Japan, United Kingdom, Canada, and New Zealand. Study involved 53,846 nurses using 
Maslach burnout inventory. Results indicated that highest levels of burnout among nurses in Japan. Medium levels of nurse burnout were reported in United Kingdom, New Zealand, and Canada. Nurses in Germany had the lowest levels of burnout out of all the 6 countries. In addition, all the nurses in the 6 countries agreed that nurse assessed quality of care diminished as a result of burnout. ${ }^{6}$

The Royal College of nursing revealed that in a survey carried out in 2013 involving 10,000 nurses, 62\% of them contemplated resigning from their job the previous year citing stress. $61 \%$ cited hectic schedules as being a hindrance to providing good quality care and $83 \%$ felt an increase in workload which has seen 5000 nurses leaving the profession in a three year period.?

Naude \& Rothmann reported that burnout has also been associated with reduced organizational efficiency and work-related problems such as employee turnover, low morale, poor quality of care, lower productivity, absenteeism and interpersonal problems. This situation can lead to compromised social interaction, not only at work place but also in the community where the nurses belong which may negatively impact the social and family lives of the professionals. ${ }^{8}$ Apart from this a relationship was found between burnout and the occurrence of musculoskeletal disorders, depression, obesity, insomnia, drug abuse and alcohol intake in nurses. ${ }^{9}$ The impact may also extend to harmful consequences in patient care like medication errors and lack of appropriate attention to the care. ${ }^{8}$ Despite the existence of numerous studies conducted regarding burnout in Europe, US, Australia, parts of Africa and Asia, there are few researches conducted on this issue of interest particularly in Ethiopia. Therefore, this study was aimed to assess the magnitude of burnout and its associated factors among nurses working in five randomly selected public hospitals of Amhara regional state, Ethiopia. The study is significant for policy makers for taking corrective actions regarding to the profession, health care institutions; particularly hospitals to recognize factors related to burnout in nurses \& aid them to take corrective measures.

\section{Methods and materials}

\section{Study area and period}

The study was conducted in selected public hospitals of Amhara regional state.

Amhara region had 17 Hospitals, 520 Health Centres and 2,941 Health Posts. The study was conducted between March and April in 2017.

\section{Study design}

Institutional based cross-sectional study design was employed to describe magnitude of nurses' burnout and its associated factors among nurses working in five randomly selected public hospitals of Amhara regional state, Ethiopia.

\section{Source population}

The source population for this study was all nurses who were currently working in 17 public hospitals of Amhara regional state, Ethiopia.

\section{Study population}

The study population was all nurses working in five randomly selected public hospitals. The selected hospitals were Felege Hiwot referral hospital, Debre Tabor referral hospital, Debre Markos referral hospital, Dessie referral hospital, and Debre Birhan referral hospital. Nurses working in the above hospitals; who can meet the inclusion criteria and willing to participate in the study were my study population.

\section{Inclusion criteria and Exclusion criteria}

Nurses who were working in different departments, with work experience of 6 months and above, and who were available during data collection period and were willing to participate in the study. Nurses who were on sick, study or other leaves during the data collection period, and those who were not volunteer to participate in the study were excluded from the study.

\section{Sample size Determination}

The actual sample size for the study was determined using the formula of single population proportion formula for single proportion population.

\section{Inclusion criteria and Exclusion criteria}

Nurses who were working in different departments, with work experience of 6 months and above, and who were available during data collection period and were willing to participate in the study. Nurses who were on sick, study or other leaves during the data collection period, and those who were not volunteer to participate in the study were excluded from the study.

\section{Sample size Determination}

The actual sample size for the study was determined using the formula of single population proportion formula for single proportion population.

$$
n i=\frac{(Z a / 2)^{2} p(1-p)}{(d)^{2}}
$$

Where $\mathrm{ni}=$ Initial estimated sample size, $\mathrm{Z}=$ Confidence level (alpha, $\alpha$ ), $\mathrm{P}=$ prevalence, $\mathrm{d}=$ marginal error. To determine the sample size the following assumption was used. Magnitude of nurses' burnout was taken from a previous related study which is $56.6 \% .{ }^{22} \mathrm{~A}$ $95 \%$ confidence level, margin of error $(0.05)$

$$
n=\frac{(1.96)^{2} \times 0.566(1-0.566)}{(0.05)^{2}}=377.46=378
$$

Since the total population was 873 nurses, which was less than 10,000 I used the correction formula:

$$
n_{f}=\frac{n i}{\left(1+\frac{n i}{N}\right)}
$$

Where $\mathrm{nf}=$ final sample size, $\mathrm{ni}=$ initial sample size, $\mathrm{N}=$ total population the final sample size was 264. Taking none-response rate to be $10 \%$ using previous related research response rate $=$ $264 \times 10 \%=26.4 \approx 26$ and considering design effect. The final sample size was: $264+26+79=369$ nurses.

\section{Sampling procedure}

A random sampling technique was employed to draw the sample size from17 public hospitals currently functioning in Amhara 
regional state. Five hospitals were randomly selected and considered to participate in the study. The five hospitals were (Felege Hiwot referral hospital, Debre Tabor referral hospital, Debre Markos referral hospital, Dessie referral hospital, and Debre Birhan referral hospital. Then final sample was selected from each hospital using Proportional to size allocation formula:

$$
=\frac{n f \times n i}{N}
$$

Where: $\mathrm{ni}=$ number of nurse in each selected hospital

$\mathrm{nf}=$ final sample of the study

$\mathrm{N}=$ total number of nurses in selected hospitals.

Felege Hiwot referral hospital $=214 * 369 / 873=90.43 \approx 90$

Debre Tabor referral hospital $=144 * 369 / 873=60.86 \approx 61$

Debre Markos referral hospital $=165 * 369 / 873=69.74 \approx 70$

Dessie referral hospital $=180 * 369 / 873=76.08 \approx 76$

Debre Birhan referral $=170 * 369 / 873=71.85 \approx 72$

Systematic simple random sampling technique was used to select sample from each hospital, this was calculated by dividing population size, $N$, by the required sample size, $n$, then, the formula was: $K=N$ / $n=2$. So the selection was in every second unit in the population in each hospital from the nurses' roster.

\section{Dependent variable and Independent variable}

Nurses' burnout is dependant and personal factors: such as age, gender, marital status, educational level, years of work experience, quality of life, work satisfaction and intention to leave work within the next 12 months; work related factors: such as title of work, work area, resource availability, shift duty, work overload- and organizational factors were independent variable.

\section{Operational definitions}

Burnout: is a syndrome which characterized by emotional exhaustion (EE), depersonalization (DP) or cynicism and low personal achievements (PA). A nurse burnout is defined to have if he/she is high in emotional exhaustion or depersonalization and low regarding personal accomplishment.

Emotional exhaustion: low $(<16)$, moderate (17-26), high $(\geq 27)$.

Depersonalization: low $(<6)$, moderate $(7-12)$, high $(\geq 13)$

Personal accomplishment: low $(\leq 31)$ moderate (32-38), high $(\geq 39)$

\section{Data collection tools}

To assess magnitude of nurses' burnout and its associated factors, the Amharic version of Maslach's Burnout Inventory-Human Services Survey (MBI-HSS) was used, which comprises 22 items with 8 items for emotional exhaustion (EE), 5 items for depersonalization (DP), and 9 items personal accomplishment (PA). Each item was answered on a 7-point which ranging from never $(=0)$ to daily $(=6)$. The MBI-HSS was a self-administered questionnaire, which was reliable and valid. To obtain socio-demographic data relevant to the study participants were also asked to provide information with regard to their age, gender, marital status, educational level, title of work, area of work and years of experience, sector of employment, shift duty, work overload, health status perception, quality of life perception, job satisfaction and finally intention to leave work within the next 12 months.

\section{Data quality control}

In order to assure the quality of data the following measures were taken. Quality and reliability was assessed using pre-test which was conducted in Black lion hospital on $10 \%$ of the sample size. Training was given to three data collectors and one supervisor in each site. The data collectors were BSc nurse students who had taken from the nearest university in each study area. The principal investigator and supervisors were actively involved in supervision of the data collection. Data collectors were supervised at each site. The completed questionnaire was checked for missed values and completeness on daily basis. Data cleaning was done using EPi data version 3.7 by removing the instruments with missed values. Revisiting was done if respondents were not found in the first visit.

\section{Data collection procedures}

Self-administered structured closed ended questionnaire was prepared and designed by reviewing different similar literatures, on magnitude of nurses' burnout and its associated factors and modified in such a way that could meet the objectives of this study. The questionnaire was consisting of all the variables that directly meet the objective of the study. Questionnaire includes individual factors, work related factors, and organizational factors. Non respondents were encouraged to fill the questionnaire and were revisited at least twice and the respondents were encouraged to respond to all items in the questionnaire within the time they devoted as much as possible to minimize large non-response rate.

\section{Data processing and analysis}

Data was checked for its completeness and correctness. Data was also coded and analysed using SPSS version 22 software package. To explain the study population in relation to relevant variables, descriptive statistics such as, frequencies, and percentages were calculated. For inferential statistics logistic regressions were used to associate professional burnout with its associated factors in nurses. Result was presented in tables and charts. P-value less than 0.05 were considered to be statistically significant in all cases.

\section{Ethical consideration}

Letter of cooperation request was obtained from Institution Review Board (IRB) of Addis Ababa University College of Allied Health Sciences, Department of Nursing and Midwifery. Official letter of co-operation was written for each selected hospital from Department of Nursing and Midwifery of AAU. Letter of cooperation was given to secure permission of access to the hospitals included in the study. After obtaining permission from the hospital directors, $\&$ unit coordinators, informal (verbal) consents was obtained from the study participants, and participants were provided the information about the objectives and expected outcomes of the study. The study was not incurs any cost or expenses on the study participants apart from time cost. There was no any potential risk that caused harm for any of my study participants. Information obtained from individual participants was kept secured and confidential. Names and other identifying data of respondents were made anonymous or eliminated throughout the study process to maintain confidentiality. 


\section{Result}

\section{Nurses' socio-demographic characters}

A total of 369 nurses participate in this study, with $100 \%$ a response rate. The analysis of socio-demographic profile of nurse population showed that, there were $184(49.9 \%)$ male and $185(50.1 \%)$ female, and half $(49.7 \%)$ of them were married. $54.5 \%$ nurses were found to be between the age of $20-29$, followed by $33.3 \%$ between age of 30 39 years. With regard to educational level majority $(72.6 \%)$ were BSc and $21.4 \%$ were diploma nurses, and one third (30.6\%) nurses with 3-5 service year of experience (Table 1).

Table I Socio-demographic characteristics of nurses in public hospitals Amhara state, Ethiopia, 2017

\begin{tabular}{|c|c|c|c|}
\hline Variables & Respondents & Frequency & Percentage \\
\hline \multirow[t]{2}{*}{ Sex } & Male & 184 & $49.90 \%$ \\
\hline & Female & 185 & $50.10 \%$ \\
\hline \multirow[t]{4}{*}{ Age } & $20-29$ years & 201 & $54.50 \%$ \\
\hline & $30-39$ years & 123 & $33.30 \%$ \\
\hline & $40-49$ years & 40 & $10.80 \%$ \\
\hline & $>50$ years & 5 & $1.40 \%$ \\
\hline \multirow[t]{5}{*}{$\begin{array}{l}\text { Service year of } \\
\text { experience }\end{array}$} & $<3$ years & 99 & $26.80 \%$ \\
\hline & $3-5$ years & 113 & $30.60 \%$ \\
\hline & $6-10$ years & 104 & $28.20 \%$ \\
\hline & $11-15$ years & 37 & $10.00 \%$ \\
\hline & $>15$ years & 16 & $4.30 \%$ \\
\hline \multirow[t]{4}{*}{ Marital status } & Single & 168 & $45.50 \%$ \\
\hline & Married & 183 & $49.65 \%$ \\
\hline & Divorced & 12 & $3.30 \%$ \\
\hline & Widowed & 6 & $1.60 \%$ \\
\hline Current educational & Diploma nurse & 79 & $21.40 \%$ \\
\hline \multirow[t]{2}{*}{ Level } & BSC nurse & 268 & $72.60 \%$ \\
\hline & MSC and above & 22 & $6.00 \%$ \\
\hline
\end{tabular}

\section{Work-related nurse characters}

The analysis work- related factors affecting burnout two-third $(65.9 \%)$ nurses were working in wards, majority $(81 \%)$ of them were staff nurses, and also majority nurses $(75.3 \%)$ have intention to leave their current work within the next 12 months. Regarding to resources availability in the hospital, majority $(71.5 \%)$ of nurses were working in their hospital without enough resources, most (92.4\%) nurses worked in their respective units where there was excessive workload, and two-third (67.2\%) nurses work in alternating duty shift. There were also considerable portion of nurses had poor health status (13.8\%), and half (51.8\%) of nurses had poor work satisfaction, and health problems related with their job, there were around $26.3 \%$ nurses were suffer from headache (Table 2) (Figure 1).
Table 2 Work-related characters of nurses in public hospitals, Amhara state, Ethiopia, 2017

\begin{tabular}{|c|c|c|c|}
\hline Variables & Respondents & Frequency & Percentage (\%) \\
\hline \multirow[t]{3}{*}{ Current duty shift } & Day shift & 102 & $27.60 \%$ \\
\hline & Night shift & 19 & $5.10 \%$ \\
\hline & Alternate shift & 248 & $67.20 \%$ \\
\hline \multirow[t]{3}{*}{ Current work unit } & Wards & 243 & $65.90 \%$ \\
\hline & Emergency & 70 & $19 \%$ \\
\hline & $\mathrm{ICU}$ & 56 & $15.20 \%$ \\
\hline \multirow[t]{3}{*}{ Job title } & Staff nurses & 201 & $81 \%$ \\
\hline & Head nurses & 38 & $10.30 \%$ \\
\hline & Specialist nurses & 32 & $8.70 \%$ \\
\hline \multirow{2}{*}{$\begin{array}{l}\text { Presence of work- } \\
\text { over load }\end{array}$} & Yes & 341 & $92.40 \%$ \\
\hline & No & 28 & $7.60 \%$ \\
\hline \multirow[t]{2}{*}{$\begin{array}{l}\text { Intention to leave } \\
\text { current work }\end{array}$} & Yes & 278 & $75.30 \%$ \\
\hline & No & 91 & $24.70 \%$ \\
\hline \multirow[t]{3}{*}{$\begin{array}{l}\text { Resources } \\
\text { availability }\end{array}$} & Good & 13 & $3.50 \%$ \\
\hline & Fair & 92 & $24.90 \%$ \\
\hline & Poor & 264 & $71.50 \%$ \\
\hline \multirow{3}{*}{$\begin{array}{l}\text { Current health } \\
\text { status }\end{array}$} & Good & 215 & $58.30 \%$ \\
\hline & Fair & 103 & $27.90 \%$ \\
\hline & Poor & 51 & $13.80 \%$ \\
\hline \multirow[t]{3}{*}{ Work satisfaction } & Good & 28 & $7.60 \%$ \\
\hline & Fair & 150 & $40.70 \%$ \\
\hline & Poor & 191 & $51.80 \%$ \\
\hline \multirow[t]{6}{*}{ Health problems } & Headache & 97 & $26.30 \%$ \\
\hline & Backache & 59 & $16.00 \%$ \\
\hline & Depression & 52 & $14.10 \%$ \\
\hline & Insomnia & 57 & $15.40 \%$ \\
\hline & Hypertension & 9 & $2.40 \%$ \\
\hline & Others & 95 & $25.70 \%$ \\
\hline
\end{tabular}

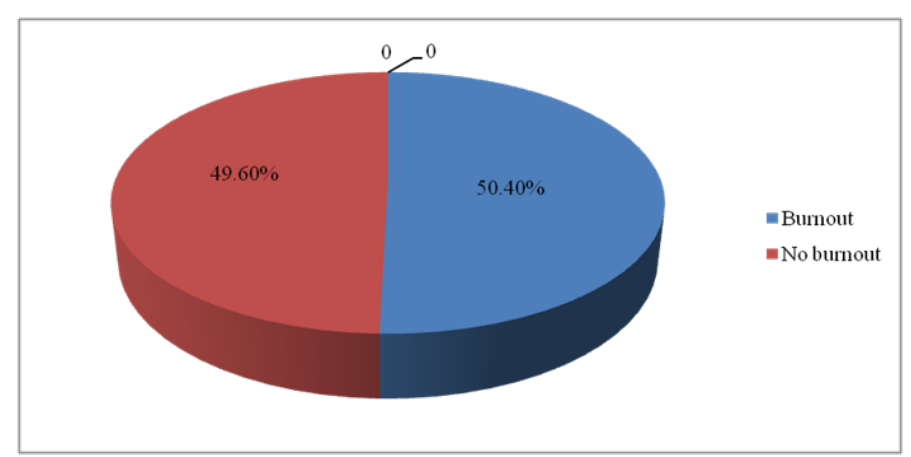

Figure I Prevalence of nurses' burnout in public hospitals of Amhara region, Ethiopia, 2017. 


\section{Prevalence of nurse's professional burnout}

From total of 369 participants, $186(50.4 \%)$ suffered from professional burnout. Among those respondents 241 nurses (65.3\%), 161 (43.6\%), and 164 nurses (44.4\%) scored had high level of Emotional Exhaustion (EE) and Depersonalization (DP) low personal achievement (PA) sub-scales respectively, which shows that a significant number of respondent nurses had high level of professional burnout. A nurse burnout is, if a nurse has high scores in emotional exhaustion or depersonalization low in personal accomplishment subscales (Table 3 ).

Table 3 Description of sub-scales of MBI-HSS in nurses' burnout, Amhara, Ethiopia, 2017

\begin{tabular}{llll}
\hline Sub-scales & High & Moderate & Low \\
\hline Emotional Exhaustion & $24 I(65.3 \%)$ & $107(29 \%)$ & $2 I(5.7 \%)$ \\
Depersonalisation & $16 I(43.6 \%)$ & $80(21.7 \%)$ & $128(34.7)$ \\
Personal Achievement & $82(22.2 \%)$ & $123(33.4 \%)$ & 164 \\
\hline
\end{tabular}

\section{Associations of Nurses Burnout}

Bivariate logistic regression was made among different variables. Nurses sex, age, marital status, service unit, service year, educational status, presence of work overload, current health status, intention to leave within 12 months ,health problem and work satisfaction had association with nurse professional burn out in bivariate logistic regression analysis. All variables that have association with the outcome variables in bivariate logistic regression analyses were included in the multiple logistic regression models. After controlling for the effects of potentially confounding variables using multiple logistic regression; nurses' educational status, service year of experience, work overload, health status and intention to leave their work were significantly associated with nurse professional burnout.

Diploma nurses were 3.7 times $[\mathrm{AOR}=3.66 ; 95 \% \mathrm{CI}:(1.11$, 12.01)] more likely for professional burnout than those MSC and above. Similarly nurses with work experience of 3-5 years were nearly 2 times $[\mathrm{AOR}=1.94$; $95 \% \mathrm{CI}:(1.11,3.38)]$ more likely for professional burnout than nurses with work experience of less than 3 years. Nurses working with no work load were $57 \%$ [AOR $=0.43$; $95 \%$ CI: $(0.19,0.99)]$ less likely for burnout than those who were working in excessive work load. Additionally nurses with fair health status were nearly 2.3 times [AOR $=2.27 ; 95 \% \mathrm{CI}:(1.18,4.37)$ more likely prone to burnout than those with good health status; and nurses suffer from depression were 2.3 times $[\mathrm{AOR}=2.32 ; 96 \% \mathrm{CI}$ : $(1.14$, 4.73) more likely risk for burnout compared to those nurses with other health problems. Finally nurses who had intention to leave their current work were $59 \%$ [AOR $=0.41 ; 95 \% \mathrm{CI}:(0.25,0.67)$ less likely for professional burnout compared to those who had no intention to leave their work (Table 4).

Table 4 Factors affecting burnout among nurses in public hospitals, Amhara Regional state, Ethiopia, 2017

\begin{tabular}{|c|c|c|c|c|c|c|}
\hline \multirow[t]{2}{*}{ Variables } & \multicolumn{2}{|c|}{ Nurses" burnout } & \multicolumn{2}{|c|}{ Bivariate logistic regression } & \multicolumn{2}{|c|}{ Multivariate logistic regression } \\
\hline & Yes & No & COR( $95 \% \mathrm{Cl})$ & P-value & AOR (95\%Cl) & P-value \\
\hline \multicolumn{7}{|l|}{ Sex } \\
\hline Male & $100(53.8 \%)$ & $84(46 \%)$ & I & & & \\
\hline Female & $86(46.2 \%)$ & $99(54 \%)$ & I.37[0.91-2.06] & 0.131 & $0.89[0.56-1.45]$ & 0.657 \\
\hline Total & $186(100 \%)$ & $183(\%)$ & & & & \\
\hline \multicolumn{7}{|l|}{ Age } \\
\hline $20-29$ & $98(52.7 \%)$ & $103(56.3 \%)$ & 1 & & & \\
\hline $30-39$ & $60(32.3 \%)$ & $63(34.4 \%)$ & $0.99[0.638-I .565]$ & 0.997 & I.56[0.25-9.58] & 0.63 \\
\hline $40-49$ & $25(13.4 \%)$ & $15(8.2 \%)$ & $0.57[0.284-|| 47]$. & 0.115 & $3.65[0.409-32.67]$ & 0.25 \\
\hline$>50$ & $3(1.6 \%)$ & $2(1.1 \%)$ & $0.634[0.104-3.878]$ & 0.622 & $0.89[0.13-5.95]$ & 0.9 \\
\hline Total & $186(100 \%)$ & $183(100 \%)$ & & & & \\
\hline \multicolumn{7}{|l|}{ Marital status } \\
\hline Single & $90(48.4 \%)$ & $78(42.6 \%)$ & I & & & \\
\hline Married & $84(45.2 \%)$ & $99(54.1 \%)$ & $\mathrm{I} .36[0.893-2.07]$ & 0.151 & $0.367[0.05-2.77]$ & 0.33 \\
\hline Divorced & $9(4.8 \%)$ & $3(1.6 \%)$ & $0.385[0.10 \mathrm{I}-\mathrm{I} .47 \mathrm{I}]$ & 0.163 & $0.49[0.07-3.43]$ & 0.47 \\
\hline Widowed & $3(1.6 \%)$ & $3(1.6 \%)$ & $\mathrm{I} .154[0.226-5.88]$ & 0.863 & $0.24[0.05-1.01]$ & 0.51 \\
\hline Total & $186(100 \%)$ & $183(100 \%)$ & & & & \\
\hline \multicolumn{7}{|l|}{ Service unit } \\
\hline Medical Ward & $57(30.6)$ & $34(18.6)$ & I & & & \\
\hline Surgical ward & $38(20.4 \%)$ & $34(18.6 \%)$ & $\mathrm{I} .5[0.8-2.8 \mathrm{II}]$ & 0.206 & $0.23[0.03-1.94]$ & 0.18 \\
\hline Pediatrics ward & $31(16.7 \%)$ & $39(21.3 \%)$ & $2.109[1.118-3.979]$ & 0.021 & $0.43[0.09-2.02]$ & 0.28 \\
\hline
\end{tabular}


Table Continued....

\begin{tabular}{|c|c|c|c|c|c|c|}
\hline \multirow[t]{2}{*}{ Variables } & \multicolumn{2}{|c|}{ Nurses" burnout } & \multicolumn{2}{|c|}{ Bivariate logistic regression } & \multicolumn{2}{|c|}{ Multivariate logistic regression } \\
\hline & Yes & No & $\operatorname{COR}(95 \% \mathrm{Cl})$ & P-value & AOR (95\%Cl) & P-value \\
\hline Emergency & $34(\mid 8.3 \%)$ & $36(19.7 \%)$ & I.775[0.943-3,34I] & 0.075 & $0.74[0.156-3.47]$ & 0.69 \\
\hline $\mathrm{ICU}$ & $23(12.4 \%)$ & $33(18 \%)$ & $2.405[1.217-4.753]$ & 0.012 & $0.56[0.118-2.66]$ & 0.46 \\
\hline Gynecology & $3(1.6 \%)$ & $7(3.8 \%)$ & $3.912[0.948-16.145]$ & 0.059 & $0.66[0.13-3.25]$ & 0.62 \\
\hline Total & $186(100 \%)$ & $183(100 \%)$ & & & & \\
\hline \multicolumn{7}{|c|}{ Year of experience } \\
\hline \multicolumn{7}{|l|}{$<3$ years } \\
\hline $3-5$ years & $58(31.2 \%)$ & $4 \mathrm{I}(22.4 \%)$ & I & & & \\
\hline $6-10$ years & $47(25.3 \%)$ & $66(36.1 \%)$ & $1.98[1.15-3.44]$ & 0.014 & $1.94[1.11-3.38]$ & $0.02^{*}$ \\
\hline $11-15$ years & $55(29.6 \%)$ & $49(26.8 \%)$ & $1.26[0.723-2.196]$ & 0.414 & $0.69[0.16-3.14]$ & 0.64 \\
\hline$>15$ years & $17(9.2 \%)$ & $20(10.9 \%)$ & I.67[0.778-3.56] & 0.189 & $0.59[0.14-2.45]$ & 0.47 \\
\hline \multirow[t]{2}{*}{ Total } & $9(4.8 \%)$ & $7(3.8 \%)$ & I.I [0.379-3.194] & 0.86 & $\mathrm{I} .53[0.47-5.0 \mathrm{I}]$ & 0.48 \\
\hline & $186(100 \%)$ & $183(100 \%)$ & & & & \\
\hline \multicolumn{7}{|l|}{ Duty shift } \\
\hline Day shift & $53(28.5 \%)$ & $49(26.8 \%)$ & $0.91[0.57-1.4]$ & 0.69 & $0.98[0.55-1.77]$ & 0.97 \\
\hline Night shift & $10(5.4 \%)$ & $9(4.9 \%)$ & $0.89[0.35-2.25]$ & 0.8 & I.07[0.42-2.8] & 0.89 \\
\hline Alternating shift & $123(66.1 \%)$ & $125(68.3 \%)$ & I & & & \\
\hline Total & $186(100 \%)$ & $183(100 \%)$ & & & & \\
\hline \multicolumn{7}{|l|}{ Job title } \\
\hline Staff nurse & $148(79.6 \%)$ & $15 \mid(82.5 \%)$ & I & & & \\
\hline Head nurse & $17(9.2 \%)$ & $15(8.2 \%)$ & $0.87[0.42-1.79]$ & 0.69 & $0.79[0.36-1.73]$ & 0.56 \\
\hline Specialist nurse & $21(11.3 \%)$ & $17(9.3 \%)$ & $0.79[0.4-1.56]$ & 0.5 & $0.92[0.36-2.4]$ & 0.87 \\
\hline Total & $186(100 \%)$ & $183(100 \%)$ & & & & \\
\hline \multicolumn{7}{|c|}{ Presence of work load } \\
\hline \multicolumn{7}{|l|}{ Yes } \\
\hline No & 177 & 164 & I & & & \\
\hline Total & 9 & 19 & $0.44[0.19-0.99]$ & 0.049 & $0.43[0.19-0.99]$ & $0.047^{*}$ \\
\hline CONTINUED.. & $186(100 \%)$ & $183(100 \%)$ & & & & \\
\hline \multicolumn{7}{|c|}{ Resource availability } \\
\hline \multicolumn{7}{|l|}{ Good } \\
\hline \multicolumn{7}{|l|}{ Fair } \\
\hline Poor & $5(2.7 \%)$ & $8(4.3 \%)$ & I.8[0.56-5.5] & 0.34 & $0.65[0.2-2.5]$ & 0.46 \\
\hline \multirow[t]{3}{*}{ Total } & $43(23.1 \%)$ & $49(26.8 \%)$ & $1.25[0.78-2.01]$ & 0.36 & $0.84[0.52-1.36]$ & 0.48 \\
\hline & $138(74.2 \%)$ & $126(68.9 \%)$ & I & & & \\
\hline & $186(100 \%)$ & $183(100 \%)$ & & & & \\
\hline \multicolumn{7}{|l|}{ Educational status } \\
\hline \multicolumn{7}{|l|}{ Diploma } \\
\hline BSC & $35(\mid 8.8 \%)$ & $44(24 \%)$ & $3.35[1.18-9.47]$ & 0.022 & $3.66[1.11-12.01]$ & $0.03^{*}$ \\
\hline MSC & $135(72.6 \%)$ & $133(72.7 \%)$ & I & & & \\
\hline \multirow[t]{2}{*}{ Total } & $16(8.6 \%)$ & $6(3.3 \%)$ & I.4[0.56-I.74] & 0.65 & $\mathrm{I} .53[0.47-5.0 \mathrm{I}]$ & 0.48 \\
\hline & $186(100 \%)$ & $183(100 \%)$ & & & & \\
\hline
\end{tabular}


Table Continued....

\begin{tabular}{|c|c|c|c|c|c|c|}
\hline \multirow[t]{2}{*}{ Variables } & \multicolumn{2}{|c|}{ Nurses" burnout } & \multicolumn{2}{|c|}{ Bivariate logistic regression } & \multicolumn{2}{|c|}{ Multivariate logistic regression } \\
\hline & Yes & No & COR(95\%CI) & P-value & AOR (95\%CI) & P-value \\
\hline \multicolumn{7}{|c|}{ Current work satisfaction } \\
\hline \multicolumn{7}{|l|}{ Good } \\
\hline Fair & $8(4.3 \%)$ & $20(10.9 \%)$ & $3.6[1.52-8.64]$ & 0.004 & I.78[0.65-4.84] & 0.26 \\
\hline Poor & $65(34.9 \%)$ & $85(46.4 \%)$ & $1.89[1.23-2.9]$ & 0.004 & I.I2[0.7I-I.96] & 0.53 \\
\hline \multirow[t]{2}{*}{ Total } & II3(60.8\%) & $78(42.6 \%)$ & 1 & & & \\
\hline & $186(100 \%)$ & $183(100 \%)$ & & & & \\
\hline \multicolumn{7}{|c|}{ Intention to leave current work } \\
\hline \multicolumn{7}{|l|}{ Yes } \\
\hline No & $156(83.9 \%)$ & $122(66.7 \%)$ & 1 & & & \\
\hline \multirow[t]{2}{*}{ Total } & $30(16.1 \%)$ & $61(33.3 \%)$ & $2.6[1.58-4.27]$ & $<0.001$ & $0.4 \mathrm{I}[0.25-0.67]$ & $<0.001 *$ \\
\hline & $186(100 \%)$ & $183(100 \%)$ & & & & \\
\hline \multicolumn{7}{|c|}{ Current health status } \\
\hline \multicolumn{7}{|l|}{ Good } \\
\hline Fair & $96(51.6 \%)$ & $119(65 \%)$ & 1 & & & \\
\hline Poor & $56(30.1 \%)$ & $47(25.7 \%)$ & $0.68[0.42-1.09]$ & 0.12 & $2.27[1.18-4.37]$ & $0.024^{*}$ \\
\hline \multirow[t]{2}{*}{ Total } & $34(18.3 \%)$ & $17(9.3 \%)$ & $0.4[0.21-0.77]$ & 0.006 & I.59[0.78-3.25] & 0.2 \\
\hline & $186(100 \%)$ & $183(100 \%)$ & & & & \\
\hline \multicolumn{7}{|c|}{ Health problems } \\
\hline Headache & $4 \mathrm{I}(22 \%)$ & $54(29.5 \%)$ & I.I8[0.67-2.09] & 0.55 & $0.84[0.47-\mathrm{I} .48]$ & 0.54 \\
\hline Backache & $32(17.2 \%)$ & $27(\mid 4.8 \%)$ & $0.76[0.4-1.45]$ & 0.41 & $\mathrm{I} .4[0.73-2.72]$ & 0.31 \\
\hline Depression & $35(18.8 \%)$ & $17(9.3 \%)$ & $0.44[0.22-0.89]$ & 0.021 & $2.32[1.14-4.73]$ & $0.02 *$ \\
\hline Insomnia & $26(14 \%)$ & $31(16.9 \%)$ & $\mathrm{I} .2[0.56-2.1]$ & 0.83 & I.I[0.52-I.96] & 0.98 \\
\hline Hypertension & $6(3.3 \%)$ & $3(1.6 \%)$ & $0.45[0 .|1-1.9|]$ & 0.28 & $2.7[0.63-11.75]$ & 0.18 \\
\hline Others & $46(24.7 \%)$ & $5 \mathrm{I}(27.9 \%)$ & I & & & \\
\hline Total & $186(100 \%)$ & $183(100 \%)$ & & & & \\
\hline
\end{tabular}

\section{Discussion}

\section{Magnitude of nurses' burnout}

The magnitude showed that $50.4 \%$ of nurses working in public hospitals of Amhara Regional state had suffered from professional burnout. The result is relatively consistent with studies done in Addis Ababa, Ethiopia. First on the level of nurses' burnout in Emergency and ICU nurses, which found that $54.7 \%$ and second on the prevalence of nurses' burnout which reported that $56.6 \%$ of nurses were suffered from professional burnout in 2013, and 2014 respectively. ${ }^{10}$ The consistency may possibly due to similar in work environment policy like patient demand, payment system, and work load. Similarly studies done in Italian and Dutch nurses which indicted that nurses are among the human service professionals that are highly susceptible and affected by burnout with prevalence estimated between $2 \%$ and $10 \%,{ }^{11}$ because of the nature of their work. ${ }^{3,12}$ This finding indicates that the magnitude of burnout among Ethiopian nurses is more than four folds of the estimated highest prevalence of burnout level by Italian and Dutch nurses; this may probably due to difference in work load, patient demand, and development level among these countries.
Additionally a multi-country, cross-sectional study conducted in 10 European countries involving 23,159 nurses working in surgical and medical wards reported high levels of burnout among nurses in different countries: $42 \%$ England, 22\% Finland, Belgium 25\%, Germany $30 \%$, Poland $40 \%$, Ire-land $41 \%$, Norway $24 \%$, Spain $29 \%$, Netherlands $10 \%$, and Switzerland $15 \% .{ }^{13}$ The finding from this study shows that the magnitude of nurses' burnout in Amhara regional state is higher than those listed Europe countries; the difference may be possibly due to sample size difference, payment system and time of study among these countries. In this study educational status of respondents have positive association with burnout, Diploma nurses are have higher magnitude of burnout (p-0.03) than those Master Nurses. The finding of this study is consistent with a study done in Addis Ababa, Ethiopia; which found that educational status of respondents has positive association with burnout. ${ }^{14}$ Findings in other studies have also indicated that higher burnout levels among participants with comparatively lower educational status. ${ }^{15}$ This is as a result of the need to deal with a double burden of demands, excessive activities, and strict shift schedules for lower levels. Conversely, having high education level has been observed to provoke more distant attitudes among workers, which can possibly be explained 
by the higher expectations commonly, observed in more qualified professionals.

When analysing the tendency to leave the profession, it was possible to observe that a stronger desire to leave the current profession was associated with increased burnout $(\mathrm{p}-<0.001)$. Other previous study done in Addis Ababa found that slightly more than $40 \%$ of the participants reported intention to leave their current work unit within the next 12 months and burnout level was higher among those nurses. ${ }^{16}$ Similarly other studies had found similar findings and suggested that the relationship between intention to leave the profession and exhaustion lies in the excessive demands imposed by the position, whereas its relationship with depersonalization could be explained by the lack of psychological resources to deal with stressors, weakening the commitment of professionals toward their institution and profession. ${ }^{17}$ In this sense, it is possible to hypothesize that professionals not working within their preferred range of activities end up showing feelings of frustration and professional nonachievement finally ends up with changing the profession.

A positive association was observed between excessive workload and burnout ( $\mathrm{p}-0.047)$. Other similar studies have also indicated that there is consistent relation-ship between burnout, particularly on the emotional exhaustion dimension and work over load. ${ }^{1}$ A major source of burnout is an overloaded work schedule that is, having too little time and too few resources to accomplish the job. Performance suffers when work is so fast paced that workers lose a sense of community. ${ }^{18}$ This is due to; as there is excessive work load there will be no regular sleeping and eating patterns. Moreover, feelings of inadequacy may also present; as there will be more continuous tasks and demands can make nurses more vulnerable to burnout. On working experiences participants with 3-5 years were more prone burnout than those with less than three years of work experience (p-0.02). Similar study done in Addis Ababa, Ethiopia, found that nurses' service year of experience had positive association with professional burnout. ${ }^{19}$ Additionally other study also indicated that nurses who were exposed more frequently to violence (insults, threats and physical violence) to report higher levels of emotional exhaustion and depersonalization. ${ }^{20}$ Since these groups were frequently and continuously exposed with a broad range of diseases, injuries and traumatic events and threats, and overcrowded situations for long period of time this in turns easily prone for burnout.

In this study I have found that having good health status is a preventive factor for burnout (p-0.024). Other studies also indicated that existence of statistically significant association between perceptions of health status, quality of life, job satisfaction and burnout. These findings shade light on the fact that presence of burnout should be considered as an alarm to threaten professional health, which in turn to have unwanted consequences on care receiving customers. ${ }^{21}$ this result indicates that status of health at work area is related with the conditions present for performing professional activities. Finally nurses suffered from depression were more prone for professional burnout; when compared to nurses suffer with other health problems (p-0.02). Other study also indicated that a relationship was found between burnout and the occurrence mental disorders like depression, and anxiety disorders in health care workers. ${ }^{22}$ this is possibly due to with work environment characteristics like; managerial pressure, high level of concentration required, excess of tasks, and few opportunities to make decisions and to use one's own abilities.

\section{Limitation of the study}

a) There was relatively smaller sample size, even though it was adequate for this analysis, it was not sufficient to carry out more detailed analysis of differences in workplaces and burnout across different hospitals' and departments units.

b) The other limitation was that this study was limited to hospitals in Amhara regional state only due to constraints of time and fund. It would have been possible to assess differences between regional and federal nurses' experiences as well as among different regional state nurses.

c) Finally the study was cross-sectional study and can only reflect experience of nurses at the time of assessment only, and therefore, a causal relationship cannot be established between burnout and its predictors.

\section{Conclusion and recommendation}

\section{Conclusion}

This study presents a significant proportion of nurses were suffer from professional burnout due to their jobs. From the total of participants nurses half of them were suffer from professional burnout.

Statistically significant associations were identified between burnout and its associate factors: like educational level, service year of experience, work load, their intention to leave their work, current health status and health problems had statistical significant association with nurses' professional burnout.

\section{Recommendations}

Based on the results of this study half of the respondents were suffer from professional burnout, so that the following recommendations are forwarded by the author:

a) Hospital management should provide trainings which focus on stress inoculation, relaxation, time management and assertiveness programs.

b) Nurses should also work on creation of a good team spirit and sufficient peer support in their institution.

c) Hospital administration system should enhance the capacity of workers by creating rewards to cope with demands of their job.

d) The hospital management should provide counselling and anticipatory coping skills for those exposed nurses.

e) Ministry of health should create educational opportunities for nurses to upgrade themselves.

f) Finally, further and rigorous studies are recommended to identify factors that are responsible for and associated with burnout.

\section{Acknowledgments}

None.

\section{Conflicts of interest}

The author declares there are no conflicts of interest.

\section{References}

1. Maslach C. Burnout: The cost of caring. Journal of organizational Behaviour. 1982;223(1):42-46.

2. Sonnentag S, Kuttler I, Fritz C. J on stressors, emotional exhaustion, and need for recovery: a multi-source study on the benefits of psychological detachment. J. Vocation. Behav. 2010;76:355-365. 
3. Sabbah I, Sabbah H, Sabbah S, et al. Burnout among nurses: Psychometric properties of the Maslach burnout inventory-human services survey (MBI-HSS). Nursing Health Education. 2012;4(9):644-652.

4. Donley R. Challenges for Nursing in the 21st Century. Journal of advanced Nursing. 2013;62(1):107-115.

5. Vahey DC, Aiken LH, Sloane DM, et al. Nurse Burnout and Patient Satisfaction. National Institutes of health. 2014;42(2):1157-1166.

6. Poghosyan L, Clarke SP, Finlayson M, et al. Nurse Burnout and Quality of Care: Cross-National Investigation in Six Countries. National Institutes of health. 2010;33(4):288-298.

7. Royal college of nursing. Nursing shortage is very real. Journal of Advanced Nursing. 2015;65(10):2088-2096.

8. Naude JLP, Rothmann S. The validation of the Maslach burnout inventory human services survey for emergency medical technicians in Gauteng. SA Journal of Industrial Psychology. 2013;30(3):21-28.

9. Sorour A, El-Maksoud M. Relationship between musculoskeletal disorders, job demands, and burnout among emergency nurses. Adv. Emerg. Nurs. J. 2012;34(3):272-282.

10. Beckstead JW. Confirmatory factor analysis of the Maslach burnout inventory among Florida nurses. International Journal of Nursing studies. 2002;39:785-792.

11. Sotoude, Zhang. Professional burnout more among the staff. Neurology. 2010;78(18):987-992.

12. Jordan K, Fenwick J, Slavin V, et al. Level of burnout in a small population of Australian midwives. Women and Birth. 2013;45(2):556-566.

13. Pisanti R, Van der Doef M, Maes S, et al. Job characteristics, organizational conditions, and well-being among Italian and Dutch nurses: a crossnational comparison. Int. J. Nurse. Stud. 2011;48(7):829-837.

14. Ibtissam Sabbah, Hala Sabbah, Sanaa Sabbah, et al. Lebanese nurses: Psychometric properties of the Maslach burnout inventory human services survey (MBI-HSS). Journal of Health. 2012;4(9):644-652.
15. Heinen MM, van Achterberg T, Schwendimann R, et al. Nurses' intention to leave their profession: A cross sectional observational study in 10 European countries. International Journal Nursing Studies. 2013;50(2):174-184.

16. Ebling M, Carlotto MS. Burnout syndrome and associated factors among health professionals of a public hospital. Trends in Psychiatry and Psychotherapy. 2012;34(2):23-30.

17. Geurts S, Demerouti E. Work/non-work interface: A review of theories and findings. In: Schabracq MJ, Winnubst JAM, Cooper CL, editors. The handbook of work and health psychology. 2003. pp. 279-312.

18. Mohammadpoorasl A, Maleki A, Sahebihagh MH. Prevalence of professional burnout and it is related factors among nurses in Tabriz in 2010. Iranian Journal of Nursing and Midwifery Research. 2012;17(7):524-529.

19. Hudek Knežević J, Kalebić MB, Krapić N. Personality, organizational stress, and attitudes toward work as prospective predictors of professional burnout in hospital nurses. Croatian Medical Journal. 2011;52(4):538549 .

20. Adriaenssens J, P.M., J. de Jonge, Bakker AB. Specific Determinants of Intrinsic Work Motivation, Burnout and Turnover Intentions: A Study among Nurses. International Journal of Nursing Studies. 2015;52(6):649-661.

21. Bernaldo De Quiros M, Piccini AT, Gomez MM, et al. Psychological consequence of aggression in pre-hospital emergency care: cross sectional survey. Int. J. Nurs. Stud. 2014;76(1):634-651.

22. Gillespie M, Melby V. Burnout among nursing staff in accident and emergency and acute medicine: a comparative study. Nurse and health. 2013;12(6):842-851 